\title{
Development of a Training Set to Strengthen Health and Professional Skills According to the Philosophy of Sufficiency Economy of Undergraduate Students in Higher Education Institutes in Bangkok
}

\author{
Chakrit Ponathong and Prapassara Thanosawan \\ Lecturer, Ed.D. Programme in Higher Education, Srinakharinwirot University, Bangkok, Thailand
}

\begin{abstract}
This research aims to 1) study the elements of strengthening health and professional skills, 2) develop a training set to strengthen health and professional skills according to the Philosophy of Sufficiency Economy of undergraduate students and 3) evaluate the training set. The samples are students of a higher education institution in Bangkok. The samples were divided into two groups, the first group is a sample used to study the supplementary elements of strengthening health and professional skills according to the Philosophy of Sufficiency Economy. A total of 320 students were selected for phase one. The second group are sample groups used to study the effectiveness of the training set which consists of 30 students in phase two. The research tools consist of 1) a survey for strengthening health and professional skills 2) a training set and 3) the effectiveness of the training set. Data analysis was by finding the average score, standard deviation, confirmatory factor analysis, and t-test. The study of the elements of strengthening health and professional skills comprises of five elements including life plan, physical and mental health, law, Information Technology and professional skills. All five elements are appropriate. The element weight is high according to .05 level of statistical significance. The training set to strengthen the health and professional skills according to the Philosophy of Sufficiency Economy of undergraduate students is appropriate. It can be used to provide training. The results of the development of the health and professional skills of the group after the training is higher than before the training at the significant statistics .05 level, and the participants are satisfied with the training set at a very high level.
\end{abstract}

Keywords: Health and professional skills according to the Philosophy of Sufficiency Economy, training set, higher education institution in Bangkok

\section{Introduction}

Educational interdependence of the ASEAN Economic Community (AEC) is a highly important event for Thai higher education. The ASEAN Economic Integration (AEC) is seen as a step toward the convergence of ASEAN member states in terms of economic integration. The AEC integration leads to the introduction of a single market and a production base of the ASEAN member states, the free movement of goods, services, investment, capital and skilled labor, along with the establishment of the emerging CLMV economies, known as ASEAN - 4 countries: Cambodia, Laos, Myanmar and Vietnam [1]. This makes the AEC a new emerging economy powerhouse in Asia. However, based on the survey results of the Global Competitiveness report, the World Economic Forum in 2013, it was found that Thailand was ranked lower than Singapore. Malaysia, Vietnam, Indonesia and Philippines, as well as in the ranking of Times Higher Education, World University rankings in 2017 [2]. In Thailand, only 10 universities have been ranked as potential and internationally recognized higher education institutions (HEIs). These rankings focus on the concentration assessment of university research and the main factors involved in determining the ratings from teaching and learning, research (revenue and research publication), international perspectives (staff, students and research), and industrial 
revenue (education) [3]. This implies that Thai higher education institutions are in the hot seat for the engagement with intense changes and quality issues. University students have to go through immense changes in the ASEAN economic regionalisation. Some students are not highly immune to studying in higher educational institutions. A number of students have problems with the adjustments. Some students lack patience when they work. This leads to a problem with a career in the future. The Philosophy of Sufficiency Economy was introduced to help students with the adjustments and give them resiliency for studying and living. The sufficiency economy philosophy is the concept of the late King Bhumibol of Thailand. The main focus is to adhere to self-reliance and remain on the sufficiency in consumption along with immunity to extreme capitalism [4] In addition, strengthening the health and professional skills is an important factor in living, including life planning, maintaining physical and mental health, legal awareness, knowledge of information technology as well as career skills. These are an important factor in the creation of life strength and stability. Therefore, HEIs will have to strengthen the health and professional skills of students to prepare them for their future career and life. This research aims to 1) study the elements of strengthening health and professional skills, 2) develop a training set to strengthen health and professional skills according to the Philosophy of Sufficiency Economy of undergraduate students and 3) evaluate the training set.

\section{Methodology}

\subsection{Samples}

320 students from first year to their final year in five HEIs in Bangkok metropolitan in 2017 academic year were selected to study the training set to strengthen health and professional skills according to the Philosophy of Sufficiency Economy. in the final stage, the training set was trialed with 30 students from Srinakharinwirot University.

\subsection{Scope of factors}

The factor includes strengthening elements of the sufficiency economy philosophy: life planning, physical and mental health, legal awareness, information technology, and professional skills.

\subsection{Research Methods}

This research consists of research and development phases. There are 4 steps in the process.

Step 1: Document study of the elements of strengthening health and professional skills from various academics and related research from the scholars and synthesis of the preliminary results and conducted a Likert scale survey. The survey consists of 60 items. Then the survey was verified by five experts and was trialed on 30 samples to test the internal validity and reliability [5]. The survey was rated at 0.95 level of reliability, then the survey was conducted with 320 students from first year to final year in five HEIs in Bangkok metropolitan in 2017 academic year.

Step 2: Developed a training set to strengthen health and professional skills according to the Philosophy of Sufficiency Economy of undergraduate students according to the survey results and verified the training set with five experts for reliability and validity.

Step 3: Applied the training set to 30 students of Srinakharinwirot University to study the effectiveness of the training set.

Step 4: Evaluated the training set during training and after training and revised the training set as a complete training set.

\subsection{Research Tools}

The tools used to collect information include the survey of the elements of strengthening health and professional skills, a training set to strengthen health and professional skills according to the Philosophy of Sufficiency Economy of undergraduate students, and the training evaluation. 


\subsection{Data Analysis}

The data was analysed by descriptive statistics using the mean and standard deviation. To find the strengthening elements and career skills, the researchers used confirmatory factor analysis. To study the effectiveness of the training set, the dependent sample t-test was conducted.

\section{Results and Discussions}

In step one of strengthening the elements of strengthening health and professional skills, there are 5 elements including life planning, physical and mental health, legal awareness, information technology, and professional skills. The five elements have a statistically significant correlation at the .05 level, the structure of the survey, strengthening the health and professional skills created are suitable with empirical data. According to Table 1-3.

TABLE I: The correlation coefficient of the elements of strengthening health and professional of university students in higher education institutions in Bangkok

\begin{tabular}{|c|c|c|c|c|c|}
\hline Factors & Life planning & $\begin{array}{l}\text { physical and } \\
\text { mental health }\end{array}$ & $\begin{array}{c}\text { Legal } \\
\text { awareness }\end{array}$ & $\begin{array}{c}\text { Information } \\
\text { technology }\end{array}$ & $\begin{array}{c}\text { Professional } \\
\text { skills }\end{array}$ \\
\hline Life planning & 1.000 & & & & \\
\hline Physical and mental health & $0.203^{*}$ & 1.000 & & & \\
\hline Legal awareness & $0.438^{*}$ & $0.214^{*}$ & 1.000 & & \\
\hline Information technology & $0.388^{*}$ & $0.844^{*}$ & $0.705^{*}$ & 1.000 & \\
\hline Professional skills & $0.847^{*}$ & $0.180^{*}$ & $0.599^{*}$ & $0.460^{*}$ & 1.000 \\
\hline
\end{tabular}

Bartlett's Test of Sphericity $=135.257 \quad \mathrm{df}=10 \quad \mathrm{p}$-value $=.000^{*}$

Kaiser - Meyer - Olkin Measure of Sampling Adequacy $=.436$

TABLE II: Result of an analysis of the elements of strengthening health and professional of university students in higher education institutions in Bangkok.

\begin{tabular}{|c|c|c|c|c|c|}
\hline Factors & Factor Score & SE & $\mathbf{t}$ & $\begin{array}{c}\text { Standard } \\
\text { Factor Score }\end{array}$ & $\begin{array}{c}\text { Reliability } \\
\left(\mathbf{R}^{2}\right)\end{array}$ \\
\hline Life planning & 0.256 & 0.020 & $12.649^{*}$ & 0.26 & 0.4 \\
\hline Physical and mental health & 0.047 & 0.016 & $2.878^{*}$ & 0.05 & 0.029 \\
\hline Legal awareness & 0.136 & 0.012 & $11.817^{*}$ & 0.14 & 0.425 \\
\hline Information technology & 0.091 & 0.011 & $8.508^{*}$ & 0.09 & 0.236 \\
\hline Professional skills & 0.269 & 0.014 & $18.818^{*}$ & 0.27 & 0.836 \\
\hline
\end{tabular}

In the table 2, the standard factor scores in all elements are positive. It has a value from 0.05-0.27 and has a statistical significance. The highest score is the professional skill element at 0.27 , life planning at 0.26 and legal awareness at 0.14 respectively. It is important that all elements can easily measure strengthening health and professional skills of university students in higher education institutions in Bangkok as shown in Figure 1.

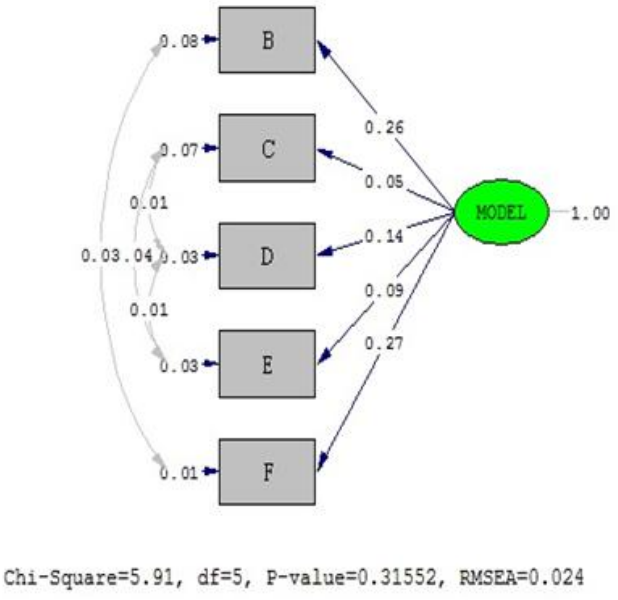

Fig. 1: Confirmatory Factor Analysis of elements of strengthening health and professional skills 
TABLE III: the consistency and Goodness of Fit of the model with empirical data of the elements of strengthening health and professional skills

\begin{tabular}{llcc}
\hline \multicolumn{1}{c}{ Index } & \multicolumn{1}{c}{ Criteria } & Model used & Test results \\
\hline$x^{2} / \mathrm{df}$ & no more than 2 & 1.182 & $\sqrt{ }$ \\
& & & $\sqrt{ }$ \\
p-value & not statistically significant & 0.31552 & $\sqrt{ }$ \\
NFI & more than 0.90 & 0.994 & $\sqrt{ }$ \\
CFI & more than 0.90 & 0.999 & $\sqrt{ }$ \\
IFI & more than 0.90 & 0.999 & $\sqrt{ }$ \\
GFI & more than 0.90 & 0.993 & $\sqrt{ }$ \\
AGFI & more than 0.90 & 0.978 & $\sqrt{ }$ \\
RMSEA & less than .05 & 0.0238 & $\sqrt{ }$ \\
RMR & closest value to 0 & 804.985 & $\sqrt{ }$ \\
CN & more than 200 & \\
\hline
\end{tabular}

This refers to the index test criteria that is used to check the consistency and Goodness of Fit of the model with empirical data [6]

In step 2 of the development of the training set, the researchers analysed the elements in the step 1, and divided them into the five elements with an integrated and other techniques. The training takes 12 hours and is divided into 3 sub-training sets. The sub-training set 1 is life planning according to the Sufficiency Economy Philosophy. The content and activities regard life planning to live in the 21 st century. The sub-training set 2 is a training to develop skills and technical understanding of physical and mental health, and legal matters in order to have a good immunity in life. The sub-training kit set 3 covers skills and techniques in information technology and professional skills as a cornerstone of the professional advancement. The training set was evaluated with the results of MEAN $=4.34$ and S.D. $=0.25$ for consistency. The overall consistency is 80 percent according to the defined criteria. The internal consistency of the training set is 85.0 percent.

For step 3, the researchers administered the training to 30 students. The researchers have organized integrated learning processes for students to engage with experiential learning. The activities include ice-breaker, develop cognitive awareness, case study, discussion, and learning through training materials such as documents, training sets, participation, and behaviour observation. After finishing, the students evaluated the effectiveness of the training set through pretest and posttest along with performance assessment of the training set. At statistically significance of .05 level, most students were satisfied with the trainings and training set. (MEAN = 4.53, S.D. $=0.25)$

TABLE IV: A comparison of the differences of before and after training of strengthening health and professional skills of university students of higher education institutions in Bangkok

\begin{tabular}{|c|c|c|c|c|c|c|}
\hline \multirow{2}{*}{ Factors } & \multicolumn{2}{|c|}{ Pre - test } & \multicolumn{2}{|c|}{ Post - test } & \multirow[b]{2}{*}{$\mathbf{t}$} & \multirow{2}{*}{ Sig. } \\
\hline & MEAN & S.D. & MEAN & S.D. & & \\
\hline Life planning & 3.62 & 0.32 & 3.94 & 0.35 & 4.32 & .000 \\
\hline Physical and mental health & 3.54 & 0.25 & 3.85 & 0.41 & 5.43 & $000^{*}$ \\
\hline Legal awareness & 3.51 & 0.22 & 4.27 & 0.28 & 9.69 & $000^{*}$ \\
\hline Information technology & 3.39 & 0.24 & 3.80 & 0.33 & 5.91 & $000^{*}$ \\
\hline Professional skills & 3.49 & 0.23 & 4.19 & 0.24 & 10.90 & $000^{*}$ \\
\hline Total & 3.51 & 0.11 & 4.01 & 0.18 & 15.86 & $000^{*}$ \\
\hline
\end{tabular}

* Statistically significant at the .05 level.

To discuss the outcome of the research, a training set to strengthen health and professional skills according to the Philosophy of Sufficiency Economy of undergraduate students in higher education institutes in Bangkok are appropriate. It provides content-oriented reliability. The standard factor scores are positive. It has a value from 0.05-0.27. The maximum scores are 0.27 and 0.26, respectively, in accordance with the concept of Sinlarat [7] who emphasised on the importance of university students to set their goals with the highest determination. In the end, and the results of this research correspond to the royal speeches of the late King Bhumibol Adulyadej who stated that everybody should plan a life goal, practice virtuous acts, be sufficient and rational, have knowledge and morality and an immunity in life. With these qualities, it helps the nation thrive and steadily developed [8]. The other components include physical and mental health, information technology, and legal awareness. The standard factor scores of all the elements are positive. It can be fully concluded that the training set is identifiable with the concept of strengthening health and professional skills according to the Sufficiency 
Economy Philosophy. The result of the assessment showed that 30 students were satisfied with the training set at very high level $(\mathrm{MEAN}=4.53$, S.D. $=0.25)$.

\section{References}

[1] ASEAN Secretariat, ASEAN economic community handbook for business. Jakarta: ASEAN Secretariat, 2011.

[2] Times Higher Education, “Time Higher Education Asia University Rankings 2017,” 2017. [Online]. Available: https://www.timeshighereducation.com/.

[3] Office of the Higher Education Commission, Education in the ASEAN Economic Community. 2017. [Online]. Available: http://www.mua.go.th

[4] W. K. Aeksangsri, Life skills development teaching [in Thai]. Bangkok: Chulalongkorn University Press, 2003.

[5] L. J. Cronbach, Essential of Psychology and Education. New York: McGraw-Hill, 1984

[6] S. Angsuchot, S. Wichitwanna, and R. Pinyopanuwat, Statistics for social sciences and behavioral research: Lisrel program techniques. Bangkok: Chareondeemunkong Printing, 2009.

[7] P. Sinlarat et al., New globalization leadership in Thai higher education system, University Council: New mission of higher education [in Thai]. Bangkok: Dhurakij Pundit University, 2009.

[8] Thailand. Ministry of Interior, The ethics handbook of provincial governors [in Thai]. Bangkok: Benchamabophit Company Limited printing., 2013. 